\title{
Relationship between day-to-day variability of equatorial plasma bubble activity from GPS scintillation and atmospheric properties from Ground-to-topside model of Atmosphere and lonosphere for Aeronomy (GAIA) assimilation
}

\author{
Mamoru Yamamoto $^{1 *}$ (D) Yuichi Otsuka ${ }^{2}$, Hidekatsu $\mathrm{Jin}^{3}$ and Yasunobu Miyoshi ${ }^{4}$
}

\begin{abstract}
The relationship between day-to-day variability of equatorial plasma bubbles (EPBs) and the neutral atmosphere is studied. This study is based on the previous study in which the GPS scintillation index and the tropospheric cloud-top temperature are used as proxies for EPB activity and atmospheric perturbations, respectively, and a correlation was found between their day-to-day variations. In this paper, we maintained the same GPS scintillation data but substituted the atmospheric data via an assimilation run of the Ground-to-topside model of Atmosphere and lonosphere for Aeronomy (GAIA). Cross-correlation between the EPB activity and the atmospheric temperature is similar to the results in Ogawa et al. (Earth Planets Space 61:397-410, 2009). The new findings from our study include (1) an enhanced correlation between the EPB activity and the neutral atmosphere is found in horizontally and vertically large areas, (2) the longitudinal disturbance of atmospheric temperature and wind velocity during the EPB-active days is enhanced, and (3) the enhancement of atmospheric disturbance during the EPB-active days shows a similarity to the characteristics of large-scale wave structures in the ionosphere. These results more clearly support couplings between EPBs and the neutral atmosphere.
\end{abstract}

Keywords: Equatorial plasma bubble, GPS scintillation, GAIA model, Day-to-day variability, Atmosphere-ionosphere coupling

\section{Introduction}

Equatorial plasma bubble (EPB) is one of intense ionospheric phenomena that occur in the low-latitude and equatorial ionosphere (e.g., Kelley 2009). EPB is the phenomenon in which depletion of ionospheric plasma at the bottom side $\mathrm{F}$ region becomes unstable, and rapidly grows and upwells to an altitude of up to $1000 \mathrm{~km}$. EPBs are also called equatorial spread $\mathrm{F}$ (ESF) after the spreading nature of the F-layer trace of an ionosonde. By using VHF radar, we can measure intense radar echoes caused by EPB-associated plasma irregularities (Woodman 2009).

\footnotetext{
*Correspondence: yamamoto@rish.kyoto-u.ac.jp

${ }^{1}$ Research Institute for Sustainable Humanosphere, Kyoto University, Uji,

Kyoto 611-0011, Japan

Full list of author information is available at the end of the article
}

Intense EPBs cause severe scintillation to the radiowave communications from satellites to the ground, or degradation of positioning by global navigation satellite systems (GNSSs). There is a social demand to study EPBs and, if possible, to predict their occurrence. (Care should be taken because scintillations can sometimes occur due to the plasma irregularities on the ray path but otherwise not be associated with EPBs.)

The growth mechanism of EPBs is understood via the Rayleigh-Taylor instability (Kelley 2009). From the linear growth rate of the Rayleigh-Taylor instability, it can be seen that the ideal conditions for the phenomena are (1) a higher ionospheric altitude and (2) enhancement of the eastward electric field. The daily onset time for EPBs is mostly in the F-region sunset period because this 
period is favorable for these conditions (Yokoyama et al. 2004). The seasonal dependence of EPBs is, on the other hand, explained by the meridional symmetry of the ionosphere across the geomagnetic equator (Maruyama and Matuura 1984). Tsunoda (1985) explained the seasonal variation as being due to the enhancement of the eastward electric field when the sunset terminator is parallel to the geomagnetic field. Many studies suggest that atmospheric gravity waves can generate initial perturbations for the onset of EPBs, acting as a sort of seeding mechanism (e.g., Fritts et al. 2008; Abdu et al. 2009). However, understanding the actual process from the gravity-wave modification of the neutral atmosphere to the initiation of the EPBs still requires more study (Woodman 2009). Furthermore, studies of day-to-day variability in EPB activity, in which the connection between EPBs and the lower atmosphere should be considered, are few.

This paper aims to elucidate the relationship between EPBs and the behavior of the lower atmosphere by a combination of observations and simulations. Also, this paper is an extension of the unique study of Ogawa et al. (2006, 2009). EPB activity is obtained by GPS scintillation observations at Kototabang (0.2 S, 100.8 E) in Indonesia. Information of the atmosphere is, on the other hand, obtained from a whole-atmosphere assimilation based on the "Ground-to-topside model of Atmosphere and Ionosphere for Aeronomy (GAIA)" (Jin et al. 2011).

\section{Methods/Experimental}

\section{Concept of this study}

Ogawa et al. $(2006,2009)$ conducted unique studies on couplings between EPBs and the lower atmosphere. They used GPS L1 (1575.42 MHz) scintillation measurements at Kototabang as an indicator of EPBs and compared the day-to-day variability of the measurements to that of the outgoing longwave radiation (OLR) that represents the cloud-top temperature $T_{b b}$ in the troposphere.

Figure 1 is taken from Fig. 3 of Ogawa et al. (2009). It shows a correlation between the day-to-day variability of the S4 index from the GPS scintillation and $T_{b b}$ from the OLR. GPS-scintillation measurement was conducted at Kototabang, as indicated by a red star $(\star)$ in the figure. The circle surrounding the red star indicates the area of the scintillation measurements. The S4 index is averaged over the period 21-23 local time (LT) every day, and deviation from the March 1 to April 30 average is used. $T_{b b}$ is an hourly value, and deviation from the same-period average is obtained at each point. Ogawa et al. (2009) report that regions with a positive (red) and negative (blue) correlation coefficient $R$ exceeding \pm 0.45 appear especially in the 1400-1600 universal time (UT) panels. A high positive $R$ area exists at latitudes of $0-10 \mathrm{~N}$ and at longitudes of 75-82 E (marked as "A" in the 1500 UT panel), while high negative $R$ areas occur between $80 \mathrm{E}$ and $100 \mathrm{E}$ to the north and the south of the high positive $R$ area (marked as "B" in the 1500 UT panel). From this result, Ogawa et al. (2009) suggest a connection between EPBs around Kototabang and the tropospheric disturbances over the Indian Ocean. This research result is unique and interesting. However, their study is limited to a single altitude in the troposphere. Recent progress in this field has been attained through computer simulation of the whole atmosphere. GAIA is an atmosphere-ionosphere coupled model for Earth that was developed by researchers in Japan (Jin et al. 2011, 2012). In this paper, we expand the EPB-to-atmosphere comparisons introduced by Ogawa et al. (2009) to different altitudes/areas and to different quantities of the atmosphere by using the GAIA assimilation data.

\section{GPS scintillation}

In this paper, data of the ionospheric scintillation is the same as in Ogawa et al. (2009). The observations were conducted at Kototabang from January 2003 with three spaced GPS receivers. The intensity $I$ of a $1.574 \mathrm{GHz}$ GPS signal was sampled at $20 \mathrm{~Hz}$, and the scintillation index (S4 index) $S_{4}$ defined by $S_{4}^{2}=\left(\left\langle I^{2}\right\rangle-\langle I\rangle^{2}\right) /\langle I\rangle^{2}$, where angle brackets denote ensemble averaging, was recorded. The general behavior of $S_{4}$ from 2003 to 2007 was reported by Ogawa et al. (2009) and was as follows. (1) The scintillation intensity decreased during the period in accordance with the decreasing phase of the solar activity. (2) Scintillations were predominant in March-April and September-October near the local sunset period. (3) Clear day-to-day variabilities were found, and March-April activity exceeded September-October activity. These are known characteristics of EPBs, and we can safely use the data in the March-April months during the local sunset period as an indicator of the EPB activities.

\section{GAIA assimilation}

GAIA is a combination of three models that were independently developed, the whole-atmosphere (from troposphere to thermosphere) general circulation model (GCM), the ionosphere model, and the electrodynamics model. At the core of GAIA, there is a "coupler" module to manage differences among the three models (Jin et al. 2011). The model then simulates the Earth's entire atmosphere and ionosphere in a self-consistent manner. The advantage of GAIA over other whole-atmosphere models such as TIE-GCM is that GAIA simulates the neutral atmosphere from the Earth's surface to the thermosphere. The GAIA research group takes advantage of this and conducts the assimilation of the whole atmosphere and ionosphere based on real atmospheric data. They use Japanese 25-year Reanalysis (JRA-25) data for the atmosphere, from the ground up to an altitude of 


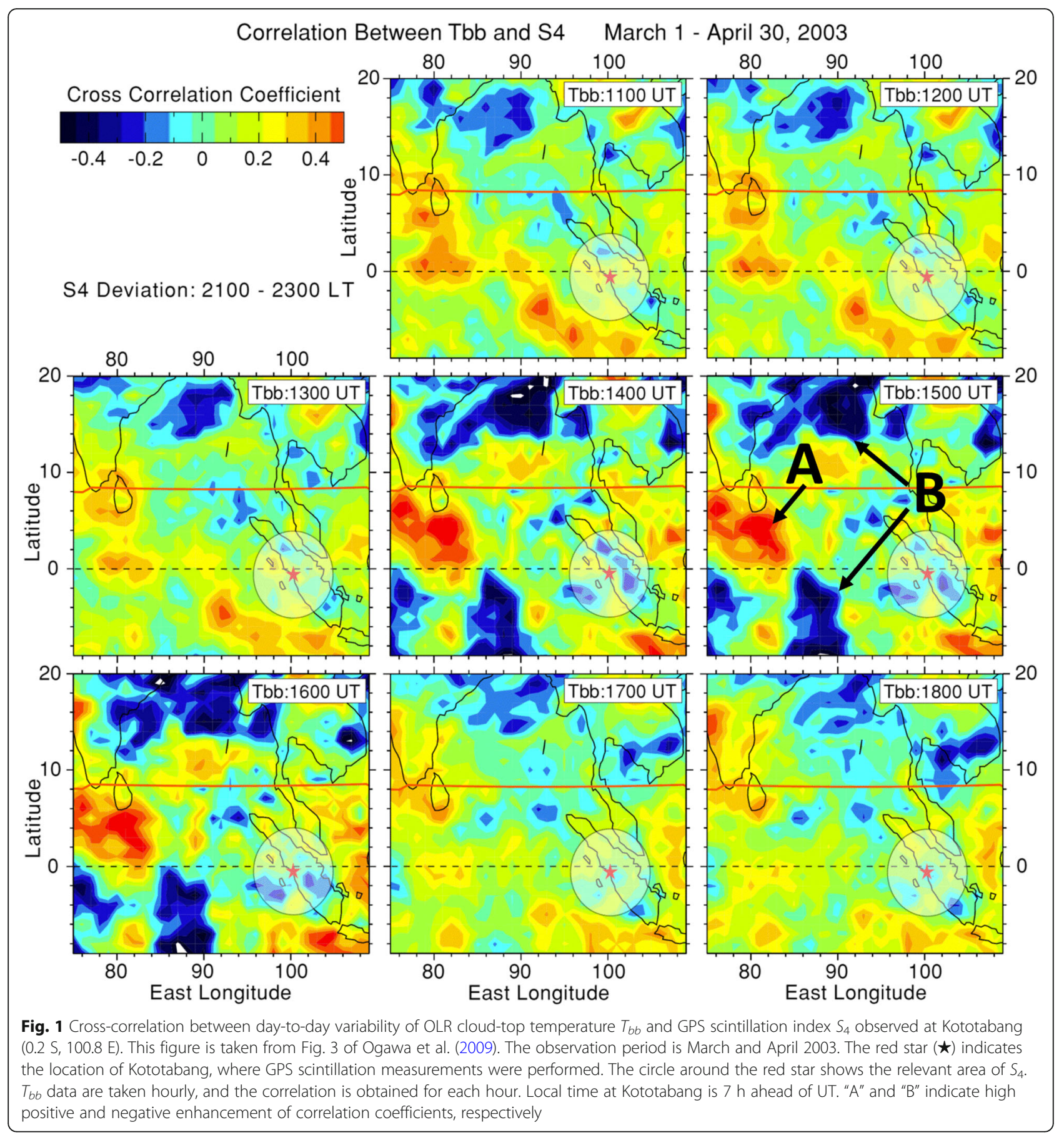

$30 \mathrm{~km}$, and a daily F10.7 index as a proxy for solar EUV radiation (Jin et al. 2012). The advantage of the GAIA assimilation is in the study of atmosphere-ionosphere coupling processes at large scales. There are previous studies of sudden stratospheric warming and its modulation of the ionospheric structures (e.g., Jin et al., 2012; Liu et al., 2014). We should note, however, that magnetospheric conditions are fixed as "moderate quiet" in the assimilation runs. Thus, this assimilation is not suitable for studying variability in the ionosphere caused by geomagnetic disturbances. Further, the geomagnetic field is a simple tilted dipole model without any time variation, which may limit use of the assimilation for studying small-scale ionospheric phenomena such as EPBs themselves. The assimilation run was conducted at the National Institute of Information and Communications Technology (NICT), and the data are provided in the NetCDF4 format. The assimilation data available to the authors were hourly atmospheric/ 
ionospheric parameters, and their resolutions were $2.8^{\circ}$ for longitude/latitude $\times 0.2$ scale height for the atmosphere, and $2.5^{\circ}$ longitude $\times 1.0^{\circ}$ latitude $\times 10 \mathrm{~km}$ altitude for the ionosphere.

\section{Results}

Our study focuses on EPB events in the period of March-April in 2003, 2004, and 2005. EPB activity was higher in 2003, moderate in 2004, and lower in 2005, in accordance with the decrease in solar activity. From the GAIA assimilation data, we first focused on day-to-day variability of temperature from March 1 to April 30 at different altitudes. Figure 2 shows the cross-correlation $R$ between day-to-day variability of $S_{4}$ and atmospheric temperature $T$ on an equal-pressure plane (a) and (b) at $500 \mathrm{hPa}$ (about $5 \mathrm{~km}$ in altitude), (c) and (d) at $2 \mathrm{hPa}$ (about $40 \mathrm{~km}$ in altitude), and (e) and (f) at $4 \times 10^{-4} \mathrm{hPa}$ (about $100 \mathrm{~km}$ in altitude). We selected $0930 \mathrm{UT}$ as the time for temperature data (a), (c), and (e), and $1530 \mathrm{UT}$ as the time for temperature data (b), (d), and (f), which correspond to local times at Kototabang of 1630 LT and 2230 LT, respectively. Each panel in Fig. 2 covers an area of $28-168 \mathrm{E}$ longitude and 37S-46 N latitude. Figure 2 is then similar to Fig. 1 in Ogawa et al. (2009) except that their OLR cloud-top temperature is substituted with the GAIA temperature at certain altitudes. Our study area is wider, and the area in Ogawa et al. (2009) is indicated by a red square in each panel.

In Fig. 2, at 1530 UT in panels (b), (d), and (f) near the western edge of the red square regions, we find a high positive $R=\sim 0.4$ at all altitudes (marked as " $C$ " in each panel). This feature is close to those marked " $\mathrm{A}$ " in Fig. 1. This feature is at similar longitudes at altitudes of 5 and $40 \mathrm{~km}$, but is slightly shifted toward the west at an altitude of $100 \mathrm{~km}$. Another similar feature is that these areas are surrounded by high negative $R$ areas such as the feature marked "B" in Fig. 1. These positive/negative high $R$ structures are clearer at an altitude of $40 \mathrm{~km}$ than at altitudes of 5 or $100 \mathrm{~km}$. At this altitude, we should note that the structures are elongated along the meridian. We can recognize the zonal train of such structures, marked as " $D$ " in panel (d), which is distributed in the latitudinal region of $9 \mathrm{~S}-19 \mathrm{~N}$. Here, a question may arise as to what the meaning of negative $R$ is. As discussed later (Fig. 4), the temperature shows enhanced longitudinal fluctuations near the equator. A negative deviation of the temperature is then associated with the negative $R$. We understand that $S_{4}$ enhancement is associated with a high correlation in both the positive and negative directions. In Fig. 2c, it shows the $R$ distribution at $0930 \mathrm{UT}$, which is close to the distribution at $1530 \mathrm{UT}$. However, from a close look at the "D" feature at an altitude of $40 \mathrm{~km}$, we can see a slight eastward motion of the pattern through time. We can see an approximately $900 \mathrm{~km}$ movement of the pattern eastward in $6 \mathrm{~h}$, which corresponds to a propagation speed of $41 \mathrm{~m} / \mathrm{s}$ eastward. The horizontal bracket in the panel covers three wavelengths of the pattern and is $6170 \mathrm{~km}$ long. The zonal wavelength is thus $2060 \mathrm{~km}$. If this pattern is measured from a fixed location, the apparent periodicity should be about $13.9 \mathrm{~h}$. This pattern of propagation is, however, not clear at different altitudes. At an altitude of $5 \mathrm{~km}$, the $R$ distributions at $0930 \mathrm{UT}$ and $1530 \mathrm{UT}$ are very close and do not show clear propagation. At an altitude of $100 \mathrm{~km}$, patterns between $0930 \mathrm{UT}$ and $1530 \mathrm{UT}$ show an overall similarity but do not hold detailed similarities such as those at altitudes of 5 or $40 \mathrm{~km}$, so that it is not easy to find the pattern propagation.

Figure 3 shows a similar analysis for data in 2004 and 2005, where we plot data at an altitude of $40 \mathrm{~km}$ only. Data in 2004 (Fig. 3a, b) show similar features as in 2003. A meridionally elongated pattern of high $R$ is seen in the 50-85 E longitude region, and it shows a slight eastward propagation with a small change in the patterns (marked as "E" in the panels). This pattern propagated eastward for $996 \mathrm{~km}$ in $6 \mathrm{~h}$. From this, we can see that the eastward propagation speed is $46 \mathrm{~m} / \mathrm{s}$, the zonal wavelength is $2010 \mathrm{~km}$, and the apparent periodicity relative to the fixed location is $12.4 \mathrm{~h}$. These numbers are close to those found in 2003. Data in 2005 (Fig. 3c, d), on the other hand, do not show clear patterns, and the $R$ level is relatively low in both the positive and negative directions. This unclear $R$ can be attributed to the fact that the EPB activity in 2005 had already decreased because of the low solar activity. We then focus on the data from 2003 and 2004 for later analysis.

What is the latitudinal distribution of the temperature perturbation? We selected an altitude of $40 \mathrm{~km}$, and calculated the longitudinal deviation of the temperature from a 5 -point running mean, and averaged them over 10 days when EPBs were the most active, during March-April in 2003 and 2004. Figure 4a, b, respectively, shows results in 2003 and 2004, and the analyses at latitudes of $32 \mathrm{~N}, 4 \mathrm{~N}$, and $23 \mathrm{~S}$ are described in each panel. In both years, the perturbation is a maximum at the latitude $4 \mathrm{~N}$, as compared with those at $32 \mathrm{~N}$ and $23 \mathrm{~S}$. These results are consistent over 2 years, but a perturbation at $4 \mathrm{~N}$ is found at the longitudes $40-80 \mathrm{E}$ in 2003 but at 40-90 $\mathrm{E}$ in 2004. This suggests that the longitudinal perturbation of the temperature is greater at low-latitude regions, with a possible enhancement on the EPB-active days.

We focus on the data at the latitude of $4 \mathrm{~N}$, and compare atmospheric perturbations on EPB-active and EPB-inactive days. We selected the three most EPB-active and EPBinactive days in each year and compared averaged GAIA data between them. As EPB activity is affected by the geomagnetic disturbance (Abdu 2012), contamination from this effect should be reduced. The "international 


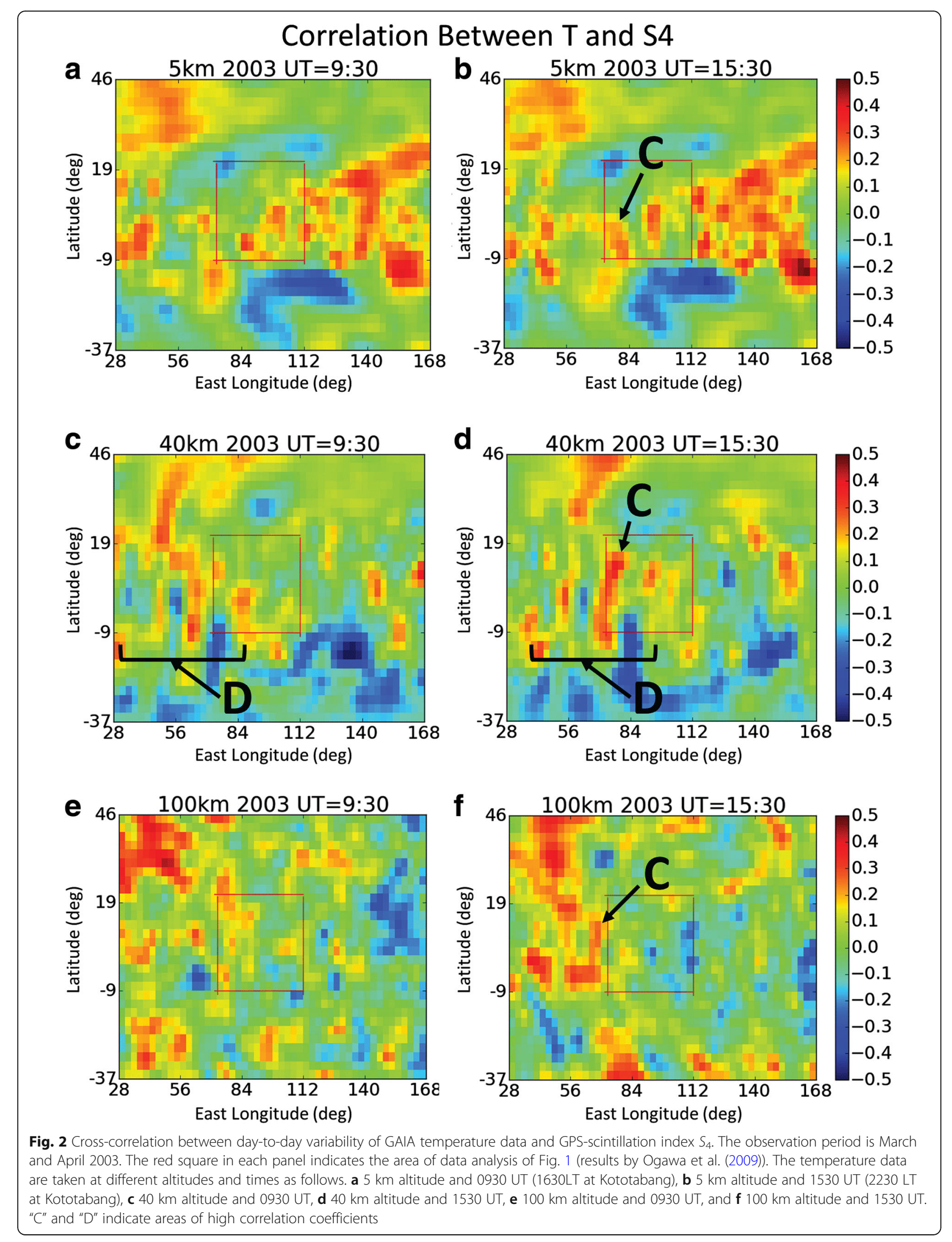




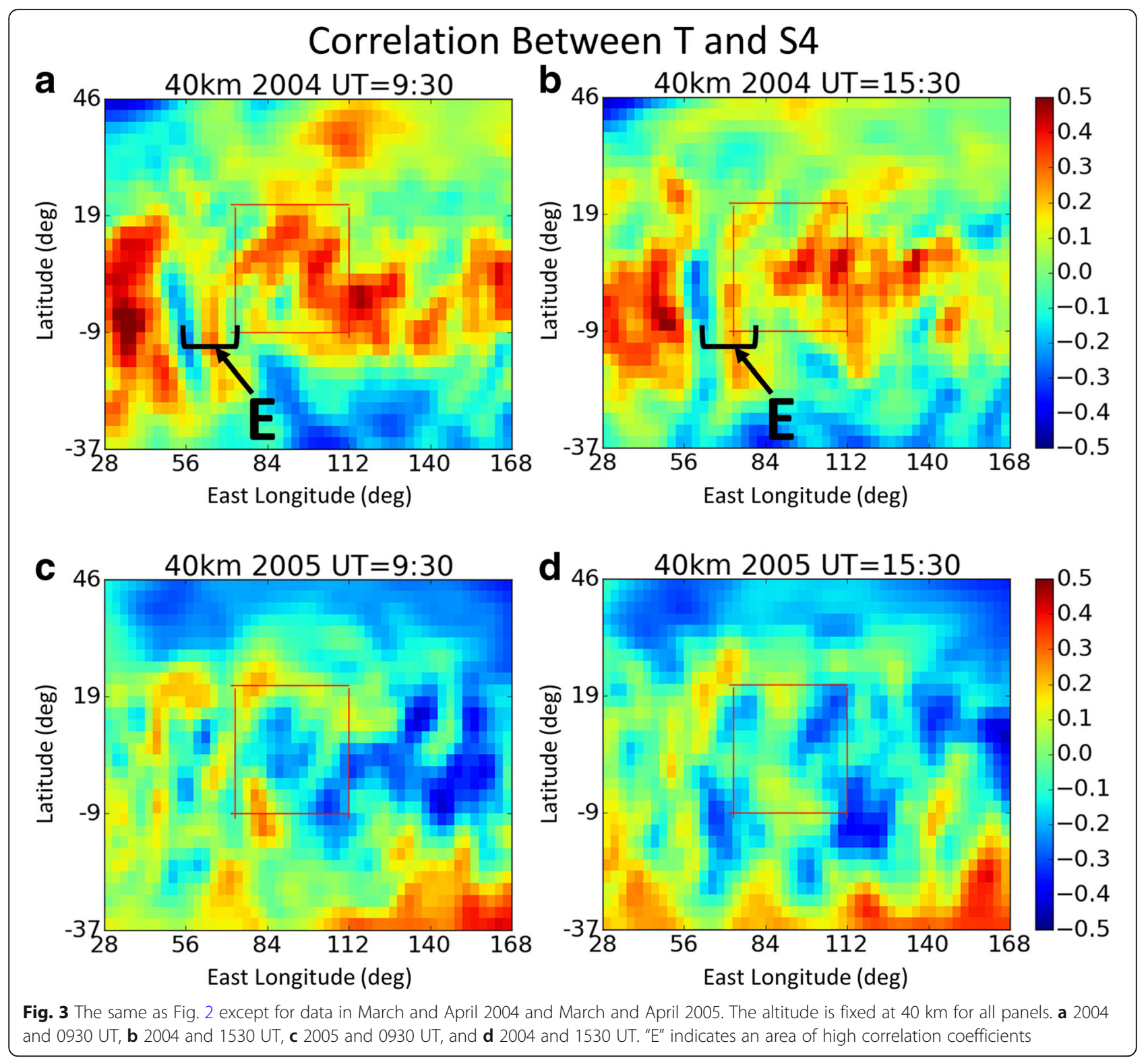

Q-days and D-days" are the 10 monthly quiet and 5 monthly disturbed days determined from the $\mathrm{Kp}$ index, respectively, and the data are available online (http://wdc. kugi.kyoto-u.ac.jp/qddays/). We excluded these international D-days from the analysis, as the geomagnetic disturbance can affect the EPB activity in both positive and negative ways. Figure 5 shows a similar analysis to that in Fig. 4 for GAIA temperature (panels (a) and (b)), eastward wind (panels (c) and (d)), and northward wind (panels (e) and (f)). Data for the three most EPB-active and EPB-inactive days are shown as solid and dashed curves, respectively, in each panel. Each 3-day average of active and inactive days is further averaged over $6 \mathrm{~h}$ from 0630 UT until 1230 UT. Data are plotted with a standard deviation (vertical bars) around the average. For example, in panels (a) and (b), temperature perturbations are enhanced on EPB-active days compared to those on EPBinactive days in both 2003 (panel (a)) and 2004 (panel (b)). The difference well exceeds the standard deviation. The longitudinal ranges of maximum temperature perturbation are $40-85 \mathrm{E}$ and $60-90 \mathrm{E}$ in 2003 and 2004, respectively. These ranges are well associated with the longitudes of the enhanced $R$ areas that are marked as "D" and "E" in Figs. 2 and 3, respectively. In the wind velocity, data in panels (c)-(f), a similar EPB-active day enhancement is persistent over both the eastward and northward wind components in both 2003 and 2004 . The amplitude of eastward wind perturbations is generally greater (2-3 times larger) than that of northward wind perturbations. In addition, the EPB-active day 

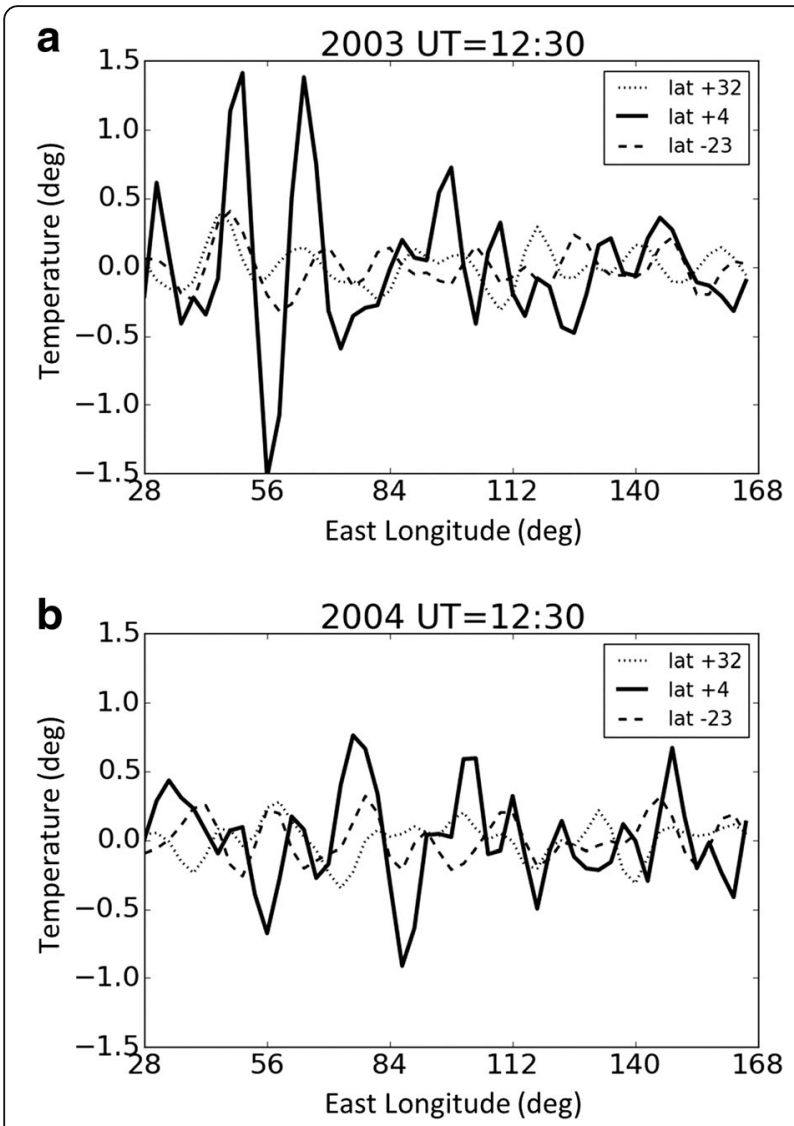

Fig. 4 Longitudinal fluctuations in GAIA temperature averaged over 10 EPB-active days in each period. The periods and timing are $\mathbf{a}$ March and April 2003 and 1230 UT and b March and April 2004 and 1230 UT. Temperature perturbation is obtained as a deviation from the zonal 5-point running mean. Solid, dashed, and dotted lines in each panel are data at 4 N, 23 S, and 32 N latitudes, respectively

enhancement in 2003 is clearer than in 2004. This yearly variation may be associated with decreased solar activity from 2003 to 2004. However, further analyses are necessary to clarify this behavior.

Finally, we show the results of the same analysis at different altitudes. Figure 6 shows a comparison of temperature perturbations between EPB-active and EPBinactive days at altitudes of 5, 20, and $100 \mathrm{~km}$ for the data in 2003. At an altitude of $5 \mathrm{~km}$ (panel (a)), amplitude of fluctuations on both EPB-active and EPB-inactive days are smaller compared with that at other altitudes. The differences between the solid and dashed curves are also small, but are enhanced more than the standard deviation in the 50-85 E longitude region. We should note that this appears at longitudes of high $R$ at an altitude of $40 \mathrm{~km}$ (Fig. 5a). Considering the general behavior of the atmosphere, in which disturbances increase with altitude in accordance with an exponential decrease in density, this small but detectable solid and dashed line difference in the troposphere may be the seed of EPB activity. At an altitude of $20 \mathrm{~km}$ (panel (b)), the EPB-active day enhancement becomes more obvious compared to the results at an altitude of $5 \mathrm{~km}$, but it is less clear compared with that at an altitude of $40 \mathrm{~km}$. At an altitude of $100 \mathrm{~km}$ (panel (c)), the EPB-active day enhancement seems existing, but it is not very clear. This is because the standard deviation around the average is much larger than at lower altitudes and may reflect the natural behavior of the upper atmosphere. Another explanation is technical: an altitude of $100 \mathrm{~km}$ is much higher than the top altitude of the data assimilation $(30 \mathrm{~km})$, so that at higher altitudes the model is less forced by real data. Padatella et al. (2014), for example, compared data assimilation results across different whole-atmosphere models and found that the model-tomodel difference increases above the stratopause region owing to variations in calculations, assumptions, and/or grid sizes across models.

Summarizing the results shown above, we suggest that differences in the atmospheric perturbations between EPB-active and EPB-inactive days are seeded in the troposphere, grow in the stratosphere, and reach the upper atmosphere.

\section{Discussion}

In this paper, we expanded the study of Ogawa et al. (2009) using the GAIA assimilation data. The GAIA assimilation has several benefits: (1) data quality is consistent and there are no missing values or outliers; (2) global data are available for all altitudes; and (3) all atmospheric parameters are available. We conducted a comparison between the day-to-day variability of EPB activity and the properties of the neutral atmosphere at several altitudes. The horizontal distribution of $R$ from our study was generally consistent with what Ogawa et al. (2009) found using the OLR data in the troposphere. Our correlation results at an altitude of $5 \mathrm{~km}$ showed a horizontally patchy distribution, which resembles the OLR results (Fig. 1). In addition, we clearly found wave-like structures at an altitude of $40 \mathrm{~km}$ and determined parameters such as their propagation speed and wavelength. Another important finding from our study was the enhanced longitudinal temperature/ wind velocity fluctuations on EPB-active days compared to those on EPB-inactive days. This feature was detected but was very small in the troposphere $(5 \mathrm{~km}$ altitude) and increased in the stratosphere (40 km altitude). The same signal was found in the upper atmosphere $(100 \mathrm{~km}$ altitude), but not very clearly. This is due to the large standard deviation of the GAIA data, which may reflect the nature of the upper atmosphere, or because the simulation of the upper atmosphere is less forced by the assimilation with real data of up to an altitude of $30 \mathrm{~km}$.

There have been several studies on the relationship between EPBs and the lower atmosphere. Li et al. (2016) compared the EPB occurrence rate determined using 


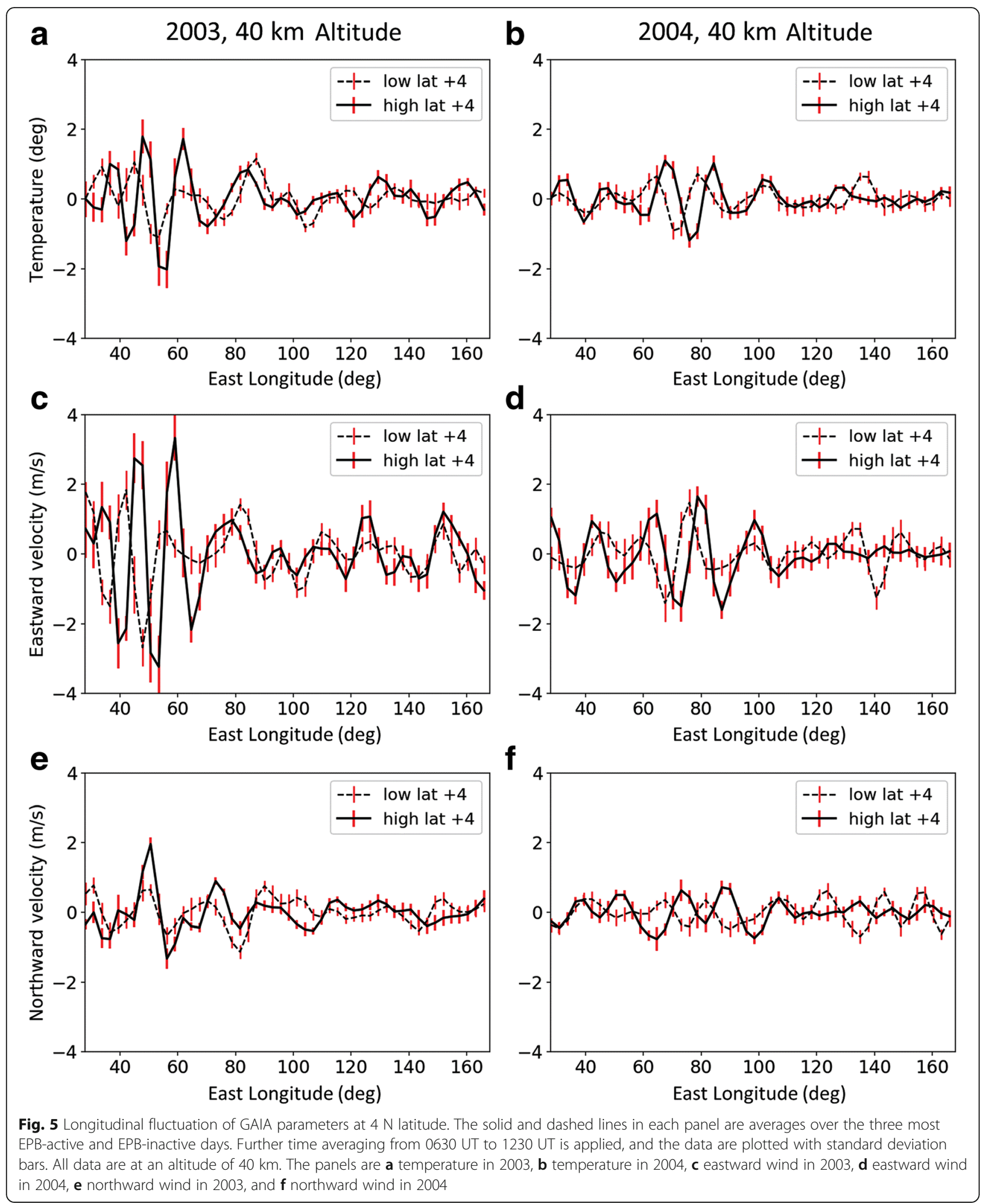



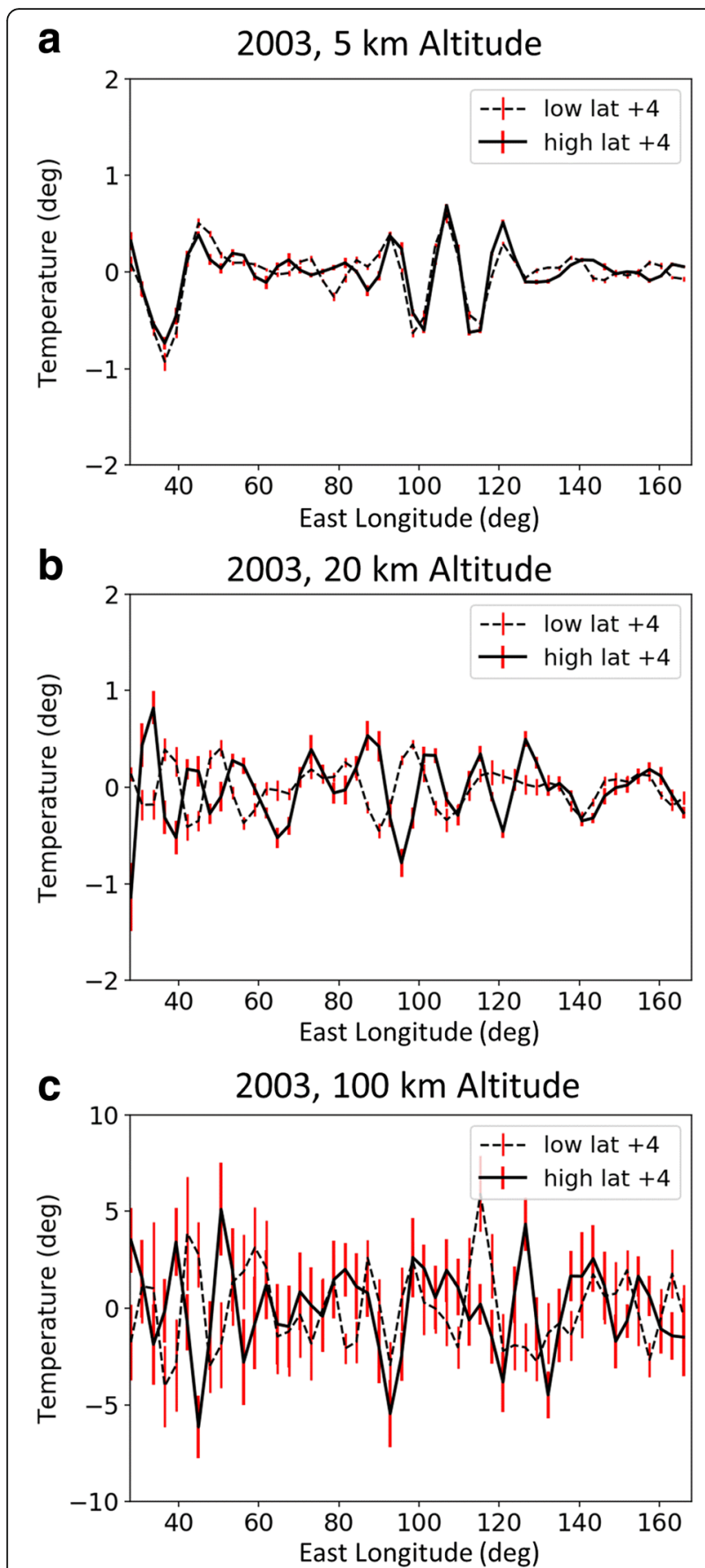

Fig. 6 Longitudinal fluctuation of GAIA temperature at $4 \mathrm{~N}$ latitude in the same format as Fig. 5. All data are for 2003, but at different altitudes: a $5 \mathrm{~km}, \mathbf{b} 20 \mathrm{~km}$, and $\mathbf{c} 100 \mathrm{~km}$

two multi-beam VHF radars separated by $9.3^{\circ}$ of longitude (the corresponding zonal distance was $1035 \mathrm{~km}$ ) and found a large difference in EPB events that were locally generated near each radar site. They explained the difference as being due to a spatial difference in the activity of the Intertropical Convergence Zone (ITCZ) in the troposphere. Liu et al. (2017) studied the global distribution of gravity waves using satellite data and showed a potential relationship to EPB occurrences. These papers provide positive support for our results. On the other hand, Su et al. (2014) used data from the ROCSAT satellite and OLR and compared the distribution of EPB activity and the OLR distribution. They did not find a good correlation between them, and this raised doubts about their relationship. The analysis by Su et al. (2014), however, is very different from ours. In order to analyze the spatial distribution of EPB occurrence with a high spatial resolution, they needed to accumulate the data over 5 years. When they showed the time variation of the EPB activity, they averaged the data within each of seven longitudinal sectors around the globe. This data smoothing may have resulted in a smearing out of the EPB-atmosphere relationship. Difficulties in EPB and OLR comparisons were seen by Ogawa et al. (2009) as well. They analyzed the wavelet power spectrum of both EPB occurrence and OLR data and tried to find a coexistence of variation. However, their results were not very clear.

In this paper, as shown in Fig. 2, we found a relationship between EPBs and the lower atmosphere, and the relationship was much clearer at an altitude of $40 \mathrm{~km}$. The enhanced temperature and wind velocity fluctuations in Fig. 5 well exceed the standard deviation for each data point. We believe that the present study has found clearer evidence of a relationship between EPB activity and the lower atmosphere than any of the research results described above. We suggest that the relationship between the EPB signal and the lower atmosphere is complicated and requires an appropriate analysis technique to elucidate it. Further research is also necessary to improve the detection of this complicated link between the EPB activity and the lower atmosphere.

One EPB-seeding hypothesis is proposed wherein EPB is generated in association with longitudinal shallow upwelling of the ionosphere with a zonal wavelength of several hundred kilometers (Tsunoda 2005, 2015). This ionospheric phenomenon is called a large-scale wave structure (LSWS). The main features of LSWSs are that they appear in the late afternoon and their amplitude increases with time, but they are generally considered stationary relative to the ground. The dual-frequency beacon experiment using C/NOFS, a low-inclination satellite, was a very suitable way of detecting LSWSs from TEC fluctuations (Thampi et al. 2009; Tulasi Ram et al. 2012). Statistical studies from sites in Vietnam and Ethiopia indicated that EPB occurrence is higher in the evening when intense LSWSs are detected (Tulasi Ram et al. 2014). The relationship between LSWSs and the lower atmosphere is not yet clear. Our enhanced atmospheric fluctuations on EPB-active days are similar to these LSWSs. We list the properties of LSWSs and our findings in Table 1. Among the five features of LSWSs, our findings are 
Table 1 Comparison between LSWS features and the results from our study

\begin{tabular}{|c|c|c|}
\hline $\begin{array}{l}\text { LSWS features } \\
\text { (Tsunoda 2005) }\end{array}$ & $\begin{array}{l}\text { Atmospheric longitudinal } \\
\text { variability on EPB-active } \\
\text { days (our findings) }\end{array}$ & Similarity \\
\hline $\begin{array}{l}\text { East-west shallow } \\
\text { perturbation of } \\
\text { ionospheric density }\end{array}$ & $\begin{array}{l}\text { East-west fluctuation of } \\
\text { temperature and wind } \\
\text { velocity }\end{array}$ & Good \\
\hline Enhancement at equator & $\begin{array}{l}\text { Large amplitude at lower } \\
\text { latitudes across equator }\end{array}$ & Good \\
\hline $\begin{array}{l}\text { Appears in afternoon to } \\
\text { dusk period }\end{array}$ & Found at any time & Good \\
\hline $\begin{array}{l}\text { Zonal wavelengths range } \\
\text { from several hundreds } \\
\text { to } 1000 \mathrm{~km}\end{array}$ & $\begin{array}{l}\text { Zonal wavelength } \\
\text { exceeded } 2000 \mathrm{~km}\end{array}$ & Inconsistency 1 \\
\hline Stationary to the ground & Eastward propagation & Inconsistency 2 \\
\hline
\end{tabular}

consistent with regard to three items. There are two inconsistencies in this comparison. One is the longer zonal wavelength in our results ("Inconsistency 1" in Table 1). The longitudinal resolution of our GAIA data is $2.81^{\circ}$, and the corresponding zonal distance at the geographic equator is $313 \mathrm{~km}$. This may limit the ability to resolve LSWS-size perturbations in GAIA. Another inconsistency is the eastward propagation in our results ("Inconsistency 2" in Table 1). Tsunoda (2005) suggested that LSWSs are not easy to detect using ground-based observations because LSWSs are generally stationary with respect to the ground. Our results indicated eastward propagation of the patterns, but the apparent periodicity on the ground was $12 \mathrm{~h}$ or longer. LSWSs are considered to last for several hours, from late afternoon to dusk. If the ground-based observations continue for a short time only, say 3-4 h, neither LSWSs nor our findings would appear wave-like and will be barely detectable. Also, we should point out that the temporal/spatial characteristics of LSWSs have not yet been well studied. The discrepancies 1 and 2 are thus not sufficient to deny the similarity between the LSWSs and our findings.

\section{Conclusions}

This study is based on the results of Ogawa et al. (2009) and expands their results by utilizing atmospheric data from the GAIA assimilation based on the atmospheric reanalysis data up to an altitude of $30 \mathrm{~km}$. We found a correlation between day-to-day variability of EPB activity from GPS scintillation and the atmospheric temperature. We found that our results are consistent with those of Ogawa et al. (2009). Also, we found that the relationship extends over a wider area than that reported by Ogawa et al. (2009), and vertically to higher altitudes. We classified the GAIA data into EPB-active and EPB-inactive days and compared the longitudinal distribution of the temperature and wind velocity. As a result, we found that the amplitude of the fluctuations on EPB-active days exceeds that on EPB-inactive days. This suggests a coupling between EPBs and the lower atmosphere. Also, the longitudinal fluctuations of the neutral atmosphere showed features that resemble LSWSs in the ionosphere. We showed that the GAIA assimilation is a useful and powerful tool for resolving as-yet-unknown day-to-day variability in EPBs. At the same time, we should note that the atmospheric data used in this study do not have sufficient resolution to accurately resolve the wave structures of LSWSs. Because the signal associated with coupling between EPBs and the lower atmosphere is complicated, more effort is necessary to improve the analysis technique. Also, improved assimilation with a finer resolution is necessary in order to elucidate many more features of this kind.

\section{Abbreviations \\ EPB: Eequatorial plasma bubble; GAIA: Ground-to-topside model of Atmosphere and lonosphere for Aeronomy; GPS: Global Positioning System; LSWS: Large-scale wave structure \\ Acknowledgements \\ We thank Keita Kitagawa and Sohei Mitani at the Graduate School of Informatics, Kyoto University, for helping in the data analysis. The GAIA assimilation was conducted on the NEC-SX8R supercomputer by the National Institute of Information and Communications Technology (NICT). The meteorological reanalysis data used by GAIA were provided by the cooperative research project of the JRA-25 long-term reanalysis by the Japan Meteorological Agency (JMA) and the Central Research Institute of the Electric Power Industry (CRIEPI). The GPS scintillation experiment was conducted by the Institute for Space-Earth Environmental Research (ISEE), Nagoya University at Kototabang, West Sumatra, Indonesia. The location is the Equatorial Atmosphere Radar site that is jointly operated by the Research Institute of Sustainable Humanosphere, Kyoto University,} and the Indonesian National Institute for Aeronautics and Space (LAPAN).

\section{Funding}

This work was supported by JSPS KAKENHI Grant Numbers $15 \mathrm{H} 02135$ and $15 \mathrm{H} 05815$. The authors thank the organizers of the Institute for Space-Earth Environmental Research "Workshop on Ionospheric Plasma Bubble Seeding and Development".

\section{Availability of data and materials}

The GAIA assimilation data were provided by NICT through the NICT Science Cloud System. The GPS scintillation experiment data were provided by ISEE, Nagoya University. The data are available under negotiation with each institution.

\section{Authors' contributions}

MY proposed the topic, and designed and conducted the study. YO provided GPS scintillation data at Kototabang, suggested the data analysis technique, and contributed to discussions in this study. $\mathrm{HJ}$ and YM provided the GAIA assimilation data, suggested the use of the data, and contributed to discussions in this study. All authors read and approved the final manuscript.

\section{Competing interests}

The authors declare that they have no competing interests.

\section{Publisher's Note}

Springer Nature remains neutral with regard to jurisdictional claims in published maps and institutional affiliations.

\section{Author details}

${ }^{1}$ Research Institute for Sustainable Humanosphere, Kyoto University, Uji, Kyoto 611-0011, Japan. ${ }^{2}$ Institute for Space-Earth Environmental Research, Nagoya University, Nagoya, Aichi 464-8601, Japan. ${ }^{3}$ National Institute of Information and Communications Technology, Koganei, Tokyo 184-8795, Japan. ${ }^{4}$ Department of Earth and Planetary Sciences, Kyushu University, Motooka, Nishi-ku, Fukuoka 819-0395, Japan. 
Received: 28 September 2017 Accepted: 10 April 2018

Published online: 02 May 2018

\section{References}

Abdu MA (2012) Equatorial spread F/plasma bubble irregularities under storm time disturbance electric fields. J Atmos Sol Terr Phys 75-76:44-56. https:// doi.org/10.1016/j.jastp.2011.04.024

Abdu MA, Alam Kherani E, Batista IS, de Paula ER, Fritts DC, Sobral JHA (2009) Gravity wave initiation of equatorial spread F/plasma bubble irregularities based on observational data from the SpreadFEx campaign. Ann Geophys 27:2607-2622 http://www.ann-geophys.net/27/2607/2009/

Fritts DC, Vadas SL, Riggin DM, Abdu MA, Batista IS, Takahashi H, Medeiros A, Kamalabadi F, Liu HL, Fejer BG, Taylor MJ (2008) Gravity wave and tidal influences on equatorial spread $F$ based on observations during the Spread $F$ Experiment (SpreadFEx). Ann Geophys 26:3235-3252 http://www.anngeophys.net/26/3235/2008/

Jin H, Miyoshi Y, Fujiwara H, Shinagawa $H$, Terada $K$, Terada N, Ishii M, Otsuka $Y$, Saito A (2011) Vertical connection from the tropospheric activities to the ionospheric longitudinal structure simulated by a new whole-Earth atmosphere-ionosphere coupled model. J Geophys Res 116:A01316. https:// doi.org/10.1029/2010JA015925

Jin H, Miyoshi Y, Pancheva D, Mukhtarov P, Fujiwara H, Shinagawa H (2012) Response of migrating tides to the stratospheric sudden warming in 2009 and their effects on the ionosphere studied by a whole atmosphereionosphere model GAIA with COSMIC and TIMED/SABER observations. J Geophys Res 117:A10323. https://doi.org/10.1029/2012JA017650

Kelley MC (2009) The Earth's ionosphere: plasma physics and electrodynamics, 2nd edn. Academic Press, Amsterdam

Li G, Otsuka Y, Ning B, Abdu MA, Yamamoto M, Wan W, Liu L, Abadi P (2016) Enhanced ionospheric plasma bubble generation in more active ITCZ. Geophys Res Lett 43:2389-2395. https://doi.org/10.1002/2016GL068145

Liu H, Miyoshi Y, Miyahara S, Jin H, Fujiwara H, Shinagawa H (2014) Thermal and dynamical changes in the zonal mean state of the thermosphere during the 2009 SSW: GAIA simulations. J Geophys Res Space Physics 119:6784-6791. https://doi.org/10.1002/2014JA020222

Liu H, Pedatella N, Hocke K (2017) Medium-scale gravity wave activity in the bottomside F region in tropical regions. Geophys Res Lett 44:7099-7105. https://doi.org/10.1002/2017GL073855

Maruyama T, Matuura N (1984) Longitudinal variability of annual changes in activity of equatorial spread F and plasma bubbles. J Geophys Res 89:10903-10912

Ogawa T, Miyoshi Y, Otsuka Y, Nakamura T, Shiokawa K (2009) Equatorial GPS ionospheric scintillations over Kototabang, Indonesia and their relation to atmospheric waves from below. Earth Planets Space 61:397-410

Ogawa T, Otsuka Y, Shiokawa K, Saito A, Nishioka M (2006) lonospheric disturbances over Indonesia and their possible association with atmospheric gravity waves from the troposphere. J Meteorol Soc Jpn 84A:327-342

Pedatella NM, Fuller-Rowell T, Wang H, Jin H, Miyoshi Y, Fujiwara H, Shinagawa $H$, Liu HL, Sassi F, Schmidt H, Matthias V, Goncharenko L (2014) The neutral dynamics during the 2009 sudden stratosphere warming simulated by different whole atmosphere models. J Geophys Res Space Physics 119:1306-1324. https://doi.org/10.1002/2013JA019421

Su S-Y, Wu CL, Liu CH (2014) Correlation between the global occurrences of ionospheric irregularities and deep atmospheric convective clouds in the intertropical convergence zone (ITCZ). Earth Planets Space 66:134 http:// www.earth-planets-space.com/content/66/1/134

Thampi SV, Yamamoto M, Tsunoda RT, Otsuka Y, Tsugawa T, Uemoto J, Ishii M (2009) First observations of large-scale wave structure and equatorial spread F using CERTO radio beacon on the C/NOFS satellite. Geophys Res Lett 36: L18111. https://doi.org/10.1029/2009GL039887

Tsunoda RT (1985) Control of the seasonal and longitudinal occurrence of equatorial scintillations by the longitudinal gradient in integrated $\mathrm{F}$ region Pedersen conductivity. J Geophys Res 90:447-456

Tsunoda RT (2005) On the enigma of day-to-day variability in equatorial spread F. Geophys Res Lett 32:L08103. https://doi.org/10.1029/2005GL022512

Tsunoda RT (2015) Upwelling: a unit of disturbance in equatorial spread F. Prog Earth Planet Sci 2:9. https://doi.org/10.1186/s40645-015-0038-5

Tulasi Ram S, Yamamoto M, Tsunoda RT, Chau HD, Hoang TL, Damtie B, Wassaie M, Yatini CY, Manik T, Tsugawa T (2014) Characteristics of large-scale wave structure observed from African and Southeast Asian longitudinal sectors. Geophys Res Space Physics 119. https://doi.org/10.1002/2013JA019712
Tulasi Ram S, Yamamoto M, Tsunoda RT, Thampi SV (2012) On the application of differential phase measurements to study the zonal large-scale wave structure (LSWS) in the ionospheric electron content. Radio Sci 47:RS2001. https://doi.org/10.1029/2011RS004870

Woodman RF (2009) Spread F-an old equatorial aeronomy problem finally resolved? Ann Geophys 27:1915-1934 https://doi.org/10.5194/angeo-27-1915-2009

Yokoyama T, Fukao S, Yamamoto M (2004) Relationship of the onset of equatorial $\mathrm{F}$ region irregularities with the sunset terminator observed with the Equatorial Atmosphere Radar. Geophys Res Lett 31(24):L24804

\section{Submit your manuscript to a SpringerOpen ${ }^{\circ}$ journal and benefit from:}

- Convenient online submission

- Rigorous peer review

- Open access: articles freely available online

- High visibility within the field

- Retaining the copyright to your article

Submit your next manuscript at $\gg$ springeropen.com 